\title{
Increase in Strength of Partially Stabilized Zirconia After Shot Peening
}

\author{
Koji TAKAHASHI ${ }^{a}$, Kae IWANAKA ${ }^{\mathrm{a},{ }^{*}}$,Toshio OSADA ${ }^{\mathrm{b}}$, Hitonobu KOIKEa ${ }^{\text {, }}$ \\ aYokohama National University, 79-5 Tokiwadai, Hodogaya, Yokohama 240-8501, Japan \\ ${ }^{\mathrm{b}}$ National Institute for Materials Science, 1-2-1 Sengen, Tukuba 305-0047, Japan \\ Correspondence: \\ Prof. Koji Takahashi \\ Professor, Faculty of Engineering, \\ Yokohama National University, \\ 79-5, Tokiwadai, Hodogaya, Yokohama, 240-8501, Japan. \\ E-mail:ktaka@ynu.ac.jp
}

\begin{abstract}
The effects of shot peening (SP) on the strength of partially stabilized zirconia (PSZ) were studied. The compressive residual stress, apparent fracture toughness $\left(K_{C}\right)$, and bending strength values of specimens subjected to SP were investigated. Results of X-ray diffraction analyses showed that SP introduced large compressive residual stress in specimens. As a result, the $K_{C}$ and bending strength values of specimens having semi-elliptical pre-cracks on their surfaces increased significantly. Shot-peened specimens having surface pre-cracks with lengths less than $140 \mu \mathrm{m}$ exhibited strength comparable to that of smooth specimens, and fractured outside the pre-crack zone, indicating that the pre-cracks were rendered harmless by SP. Thus, the introduction of a compressive residual stress by SP is an effective technique for increasing the strength of PSZ.
\end{abstract}

Keywords: partially stabilized zirconia, shot peening, residual stress, bending strength 


\section{Introduction}

Zirconia $\left(\mathrm{ZrO}_{2}\right)$ is a ceramic material with excellent mechanical properties. The fracture toughness of partially stabilized zirconia (PSZ) is higher than that of other ceramics, owing to transformation toughening whereby the tetragonal phase transforms to a stable monoclinic phase under stress [1]. Therefore, PSZ has been used for structural and medical applications, including cutting tools, bearings, valves, artificial bones and artificial joints. In these ceramic components, machining is an important process in the creation of the final product. However, the fracture toughness of PSZ (5-10 $\left.\mathrm{MPa} \mathrm{m}^{1 / 2}\right)$ is still lower than that of metallic materials. As a result, surface cracks are introduced by machining. These cracks significantly decrease the strength and the reliability of the ceramic components. In this paper, we attempt to overcome this problem by applying shot peening (SP) to PSZ.

$\mathrm{SP}$ is a common surface modification procedure used to increase the near-surface strength of metals [2]. Compressive residual stress is generated by the localized plastic deformation of the surface layer. SP can increase the fatigue strength of metals because the compressive residual stress prevents fatigue crack initiation and propagation [3-5]. Takahashi et al. carried out bending fatigue tests using high strength steel specimens containing surface cracks subjected to SP, and reported that a surface crack that reduced the fatigue limit by $50 \%$ could be rendered harmless by SP [3]. Fernández-Pariente reported that SP was able to improve the fatigue strength of low-alloy steel specimens with pre-existent defects, regardless of the defect type [4]. Sakamoto et al. investigated the effect of a surface flaw introduced after SP on the fatigue strength in medium carbon steel, and reported that the fatigue crack initiation life, fatigue crack growth life, and fatigue limit in the steel could all be increased by SP [5].

If surface cracks on structural parts can be rendered harmless through the use of the SP technique, the SP surface treatment will be a promising technique for increasing the reliability of PSZ and other ceramics. On the other hand, researchers believed that strengthening ceramics with SP would be difficult because cracks occur on a ceramic surface when SP is too strong. However, recent studies showed that the near-surface strength of ceramics could be improved by SP [6-10]. It has been reported that compressive residual stress could be introduced by SP or sandblasting near the surface in silicon nitride $\left(\mathrm{Si}_{3} \mathrm{~N}_{4}\right)$ [6,7], alumina $\left(\mathrm{Al}_{2} \mathrm{O}_{3}\right)$ [7], $\mathrm{Si}_{3} \mathrm{~N}_{4} / \mathrm{SiC}$ composite [8], yttria stabilized tetragonal zirconia (Y-TZP) [9], and PSZ [10]. Kosmac et al. reported that sandblasting increased bending strength of Y-TZP approximately $22 \%$ [9]. Ito et al. reported that compressive residual stress ranging from 250 to $340 \mathrm{MPa}$ was introduced in the near surface of PSZ, and bending strength was increased $9 \%$ by soft SP using aluminum particles [10]. However, the effects of SP on the bending strength of PSZ containing a surface crack have not yet been studied.

The objective of this study was to investigate the effects of SP on the bending strength of PSZ containing a surface crack. Specimens containing surface cracks were subjected to SP, and the effects of SP on bending strength were investigated. The size of surface cracks that can be rendered 
harmless by SP was investigated in terms of bending strength.

\section{Materials and Methods}

\subsection{Specimen preparation}

The PSZ ceramic (ZR-1, Japan Fine Ceramic Center) used in this study was commercial 3mol\% $\mathrm{Y}_{2} \mathrm{O}_{3}$ partially stabilized zirconia. The Vickers hardness (HV) and density of the PSZ was $1300 \mathrm{HV}$ and $6.1 \mathrm{~g} / \mathrm{cm}^{3}$, respectively. The specimens for the bending test were machined from a PSZ rectangular plate of $5 \times 50 \times 80 \mathrm{~mm}^{3}$. The dimensions of the specimens were $3 \times 4 \times 20 \mathrm{~mm}^{3}$. One face of the specimens was polished to a mirror-like finish. These specimens are hereafter referred to as the "Smooth" specimens.

\subsection{Shot peening and residual stress}

SP was performed on the surfaces of the specimens using a direct-pressure peening system. Commercial $\mathrm{ZrO}_{2}$ beads with a diameter of $180 \mu \mathrm{m}$ and Vickers hardness of $1150 \mathrm{HV}$ were used as the shot material. The SP conditions are listed in Table 1. The average surface roughness of the Smooth and SP specimens were $0.36 \mu \mathrm{m}$ and $0.47 \mu \mathrm{m}$, respectively. The residual stresses on the surfaces of the Smooth and SP specimens were measured using the X-ray diffraction (XRD) method. Conditions for the XRD analyses are shown in Table 2 [11]. For the measurement of residual stress, bending test specimen was used. The in-depth residual stress distributions of the samples were investigated after removing the surface layers by polishing the specimens with diamond abrasive pastes of 9.0, 3.0, and $0.5 \mu \mathrm{m}$. The residual stress in axial direction at a center part of the polished surface was measured at each layer successively. Number of measurement point at each layer was one. We confirmed that the removal of the surface layers resulted in negligible residual stress, as mentioned in section 3.1 .

\subsection{Measurement of apparent fracture toughness}

Smooth and SP specimens were prepared for measurement of the apparent fracture toughness $\left(K_{C}\right)$ at the subsurface level. The $K_{C}$ value was evaluated by the indentation fracture method, in which $K_{C}$ is estimated using the following equation in accordance with the Japan Industry Standards [12]:

$$
K_{C}=0.026 E^{1 / 2} P^{1 / 2} \frac{a}{c^{3 / 2}}
$$

where $E$ is the Young's modulus, $P$ is the indentation load, $a$ is half the diagonal length of the indentation, and $c$ is half the surface crack length $(2 c)$. Vickers indentations were made on the polished surfaces of the specimens by applying an indentation load of $49 \mathrm{~N}$ for $20 \mathrm{~s}$. The Young's modulus of the tested material was $214 \mathrm{GPa}$. 


\subsection{Crystal structure analysis}

The phase transformation induced by SP was evaluated by XRD analysis, which was performed using $\mathrm{CuK} \alpha$ radiation. The scanning angle was $25-65^{\circ}$, and the scan speed was $2 \% \mathrm{~min}$. The shot pressures were set to $0.2,0.4$, and $0.6 \mathrm{MPa}$ for the crystal structure analysis.

\subsection{Bending test and observation}

To measure the bending strength $\left(\sigma_{B}\right)$, four types of specimens were prepared. A Vickers indentation was made on the centers of the polished faces of the Smooth specimens at loads of 4.9-98 N. These specimens are called the "Pre-cracked" specimens. We then performed SP on the surfaces of the Smooth and Pre-cracked specimens. The SP conditions are listed in Table 1. These specimens are called the "Smooth+SP" and "Pre-crack+SP" specimens, respectively. The $\sigma_{B}$ values were determined by the three-point bending test; the span length for the test was $16 \mathrm{~mm}$, as shown in Fig. 1. The bending test was performed at a cross-head speed of $0.5 \mathrm{~mm} / \mathrm{min}$ at room temperature in air. The origins of the fracture were observed using optical microscopy and scanning electron microscopy (SEM).

\section{Results and discussion}

\subsection{Residual stress owing to shot peening}

Figure 2 shows the residual stress distributions of the various samples along the depth direction. The compressive residual stress on the surface of the PSZ specimen was $1400 \mathrm{MPa}$, and it reached a maximum of $1800 \mathrm{MPa}$ at a depth of $20 \mu \mathrm{m}$. With further increases in depth, stress decreased. The residual stresses of Smooth (Non-SP) specimens before and after polishing $20 \mu \mathrm{m}$ were indicated by solid squares in Fig.2. Compering these residual stresses, we confirmed that the removal of the surface layers by mechanical polishing resulted in negligible residual stress. Ito et al. reported that compressive residual stress ranging from 250-340 MPa was introduced near the surface of PSZ by soft SP using aluminum particles [10]. The value of compressive residual stress induced in the present study was much higher than that reported by Ito et al.. This was because the Vickers hardness of the shot material used in the present study was higher than that used in Ito's study [10].

For further comparison, the residual stress value of an $\mathrm{Al}_{2} \mathrm{O}_{3} / \mathrm{SiC}$ composite [13] and $\mathrm{Si}_{3} \mathrm{~N}_{4}$ [14], both subjected to SP, are also shown. After the specimens had been subjected to SP, a large compressive residual stress was introduced on the surface of the PSZ specimen, while the residual stresses in the $\mathrm{Al}_{2} \mathrm{O}_{3} / \mathrm{SiC}$ composite and $\mathrm{Si}_{3} \mathrm{~N}_{4}$ specimens were small. The compressive residual stress on the surface of the PSZ specimen was approximately two to three times higher than those on the surfaces of the $\mathrm{Al}_{2} \mathrm{O}_{3} / \mathrm{SiC}$ composite and $\mathrm{Si}_{3} \mathrm{~N}_{4}$ specimens. Therefore, it was confirmed that a compressive residual stress was efficiently introduced into the PSZ specimen.

\subsection{Apparent fracture toughness}

Figure 3 shows the effect of SP on the apparent fracture toughness $\left(K_{\mathrm{C}}\right)$ values of the various 
specimens. The $K_{\mathrm{C}}$ value of the SP specimen was $16.0 \mathrm{MPa} \bullet \mathrm{m}^{1 / 2}$; this value was $258 \%$ higher than the $K_{\mathrm{C}}$ value for the Smooth specimen, which was $4.5 \mathrm{MPa}^{\prime} \mathrm{m}^{1 / 2}$. The surface crack length $(2 c)$ of the SP specimen was smaller than that of the Smooth test specimen, as shown in Fig. 4. Further, $K_{C}$ value increased with a decrease in crack length. Thus, the improvement in the $K_{\mathrm{C}}$ value due to SP can be considered to have resulted from the compressive residual stress induced by SP, which suppressed the initiation and propagation of surface cracks.

\subsection{Crystal structure}

Figure 5 shows the XRD profiles of the Smooth and SP specimens subjected to SP at pressures of $0.2,0.4$, and $0.6 \mathrm{MPa}$. The XRD measurements were performed after polishing the specimens to a depth of $20 \mu \mathrm{m}$. This was done because the surface roughness of the specimens increased slightly after they were subjected to SP, making it difficult to identify minute peaks. A monoclinic ( $\left.\begin{array}{lll}2 & 1 & 1\end{array}\right)$ peak was confirmed in the vicinity of $45^{\circ}$ for all specimens. The monoclinic weight fractions $\left(X_{m}\right)$ under the different shot pressures were calculated using Equation (2) [11]:

$$
X_{m}=\frac{I_{m}(211)}{I_{m}(211)+I_{t}(011)}
$$

where $I_{m}\left(\begin{array}{lll}2 & 1 & 1\end{array}\right)$ and $I_{t}\left(\begin{array}{lll}0 & 1 & 1\end{array}\right)$ are the integrated intensities of the $\left(\begin{array}{lll}2 & 1 & 1\end{array}\right)$ and $\left(\begin{array}{lll}0 & 1 & 1\end{array}\right)$ peaks, respectively. Table 3 shows the half-width of the tetragonal $\left(\begin{array}{lll}0 & 0 & 1\end{array}\right)$ t peak. The half-width increased with an increase in shot pressure. This was because the crystal spacing changed owing to the local plastic deformation introduced by SP. The monoclinic weight fraction increased significantly with the increase in shot pressure, as shown in Table 3. This was attributable to the stress-induced transformation of the tetragonal phase in the PSZ to a monoclinic one, owing to the collision of the projection materials because of SP.

The compressive residual stress induced by SP in PSZ was greater than that induced in the compared materials, as described above. The Young's modulus of the PSZ is $214 \mathrm{GPa}$; this value is smaller than those of the compared materials, which are $389 \mathrm{GPa}$ [13] for the $\mathrm{Al}_{2} \mathrm{O}_{3} / \mathrm{SiC}$ composite, and $294 \mathrm{GPa}$ [14] for $\mathrm{Si}_{3} \mathrm{~N}_{4}$. Thus, it is believed that the large compressive residual stress in PSZ was derived from the fact that the plastic deformation and stress-induced transformation caused by SP in PSZ were greater in degree than those induced in the compared materials.

\subsection{Effect of SP on bending strength}

Figure 6 shows the results of the bending test for each specimen. The bending strength $\left(\sigma_{B}\right)$ of the Precracked specimens decreased significantly with an increase in pre-crack length. The $\sigma_{B}$ value of the Precracked specimen improved significantly after SP. In particular, the bending strengths of the Pre-crack+SP specimens with crack lengths of approximately $140 \mu \mathrm{m}$ or less were comparable to those of the Smooth+SP specimens. Figures 7(a) and (b) show optical micrographs of the surface of a Pre-crack+SP specimen. The Pre-cracked specimen with a crack length of $261 \mu \mathrm{m}$ had fractures in the pre-crack zone, 
as shown in Fig. 7(a). However, most of the Pre-crack+SP specimens with crack lengths of approximately $140 \mu \mathrm{m}$ and lower had fractured outside the pre-crack zone, as shown in Fig. 7(b) and 7(c). Figures 8(a) and (b) show SEM images of the fracture surfaces of the Pre-cracked and Pre-crack + SP specimens, respectively. The Pre-cracked specimen fractured in the pre-cracked area, as shown in Fig. 8(a). However, Pre-crack+SP specimens with a crack length of less than $140 \mu \mathrm{m}$ fractured outside the pre-cracked area, as shown by the arrow in Fig. 8(b) and 8(c).

These results indicate that the fracture mechanism of the Pre-crack+SP specimens with crack lengths less than $140 \mu \mathrm{m}$ was similar to that of the Smooth specimens. Therefore, surface cracks with lengths of $140 \mu \mathrm{m}$ and lower were rendered harmless by SP. It has been reported that the compressive residual stress introduced by SP is effective in preventing the propagation of fatigue cracks in metallic materials, or in rendering them harmless [3]. As with case metals, compressive residual stress induced on the surface of PSZ reduced the effective stress intensity factor at the pre-crack tips when a bending stress load was applied. As a result, the bending strength of the Pre-crack+SP specimens was improved significantly, while precracks with lengths of approximately $140 \mu \mathrm{m}$ and less were rendered harmless. Thus, the introduction of a compressive residual stress by SP is an effective technique for increasing the strength of PSZ.

\section{Conclusions}

The effects of SP on the bending strength $\left(\sigma_{B}\right)$ of a PSZ, were investigated. The primary results can be summarized as follows:

(1) The compressive residual stress induced by SP was $1400 \mathrm{MPa}$ on the surface, while it reached a maximum of $1800 \mathrm{MPa}$ at a depth of $20 \mu \mathrm{m}$. Thus, a large compressive residual stress was introduced by SP.

(2) The $K_{C}$ value at the surface of the specimens subjected to SP was $258 \%$ higher than that of the Smooth specimens. The improvement in the $K_{C}$ value was considered to be attributable to the compressive residual stress induced by SP.

(3) The phase transformation induced by SP was evaluated by XRD analysis. The results showed that SP induced a phase transformation from the tetragonal to the monoclinic phase.

(4) The $\sigma_{B}$ values of the pre-cracked specimens were significantly improved by SP. Shot-peened specimens with surface cracks whose lengths were less than $140 \mu \mathrm{m}$ fractured outside the pre-crack zone. This result indicates that the pre-cracks were rendered harmless by SP.

\section{Acknowledgments}

The authors would like to thank Prof. S. Mitsushima, Yokohama National University, and Dr.

S. Saito, NHK Spring Co., Ltd., for their assistance with the XRD measurements.

\section{References}

1. Garvie RC, Hannink RH, Pascoe RT. Ceramic steel? Nature 1975;258:703-4.

2. Suresh S. Fatigue of Materials. Cambridge University Press; 1991, p. 134-5. 
3. Takahashi K, Amano T, Ando K, Takahashi F. Improvement of fatigue limit by shot peening for high-strength steel containing a crack-like surface defect. Int. J Structural Integr 2011;2:281-92.

4. Fernández-Pariente I, Bagherifard S, Guagliano M, Ghelichi R. Fatigue behavior of nitride and shot peened steel with artificial small surface defects. Engineering Fracture Mechanics 2013;103:2-9

5. Sakamoto J, Lee Y, Cheong S. Effect of surface flaw on fatigue strength of shot-peened medium-carbon steel. Engineering Fracture Mechanics 2014;133:99-111.

6. Pfeiffer W, Frey T. Strengthening of ceramics by shot peening. J Eur Ceram Soc 2006;26:2639-45.

7. Moon WJ, Ito T, Uchimura S, Saka H. Toughening of ceramics by dislocation subboundaries. Mater Sci Eng A 2004;387-389:837-9.

8. Takahashi K, Nishio Y, Kimura Y, Ando K. Improvement of strength and reliability of ceramics by shot peening and crack-healing. J Eur Ceram Soc. 2010;30:3047-52.

9. Kosmac T, Oblak C, Jevnikar P, Funduk N, Marion L. The effect of surface grinding and sandblasting on flexural strength and reliability of Y-TZP zirconia ceramic. Dental Materials,1999;15:426-433

10. Itou Y, Suyama S, Huse T. Effect of soft shot peening on bending strength of partially stabilized zirconia. Journal of the Ceramic Society of Japan, 2003;111: 776-780 (in Japanese).

11. Tanaka K, Kurimura T, Akiniwa Y, Suzuki K, Nakamura H. X-ray residual stress measurement of yttria-partially stabilized zirconia. Trans Jpn Soc Mech Eng Ser. A, 1989;55:318-25.

12. Japan Industrial Standards R1607. Testing Method for Fracture Toughness of Fine Ceramics. Japan Standards Association, 1995.

13. Oki T, Yamamoto H, Osada T, Takahashi K. Improvement of the contact strength of $\mathrm{Al}_{2} \mathrm{O}_{3} / \mathrm{SiC}$ by a combination of shot peening and crack-healing. J Powder Techno 2013;946984.

14. Yamamoto H, Oki T, Takahashi K, Osada T. Improvement of rolling contact fatigue strength of silicon nitride by shot-peening. Trans Jpn Soc Mech Eng Ser.A, 2013;79:740-44. 


\section{Table captions}

Table 1. Shot peening conditions

Table 2. Conditions for the X-ray diffraction analyses

Table 3. Half-width of $\left(\begin{array}{lll}0 & 0 & 1\end{array}\right)_{\mathrm{t}}$, monoclinic weight fraction, and integrated intensity for the different shot pressures

\section{Figure Captions}

Fig. 1. Schematic drawing of the three-point loading system, test specimen size, and machining configuration.

Fig. 2. Relationship between residual stress and depth from surface.

Fig. 3. $K_{\mathrm{C}}$ values of the different surface-treated specimens. The error bar indicates the standard deviation.

Fig. 4. Photographs of Vickers indentations and cracks in the (a) Non-SP, and (b) SP specimens.

Fig. 5. XRD pattern of the surface of a peened PSZ specimen.

Fig. 6. Relationship between bending strength and crack length.

Fig. 7. Surface of a Pre-crack + SP specimen after the bending test; bending strengths and crack lengths of (a) $\sigma_{B}=1100 \mathrm{MPa}$ and $2 c=140 \mu \mathrm{m}$, (b) $\sigma_{B}=651 \mathrm{MPa}$ and $2 c=261 \mu \mathrm{m}$, and (c) $\sigma_{B}=1431 \mathrm{MPa}$ and $2 c=52 \mu \mathrm{m}$.

Fig. 8. SEM images showing the origins of fractures: (a) Pre-cracked specimen, $2 \mathrm{c}=120 \mu \mathrm{m}$, $\sigma_{B}=354 \mathrm{MPa}$, (b) Pre-crack+SP specimens, $2 \mathrm{c}=140 \mu \mathrm{m}, \sigma_{B}=1100 \mathrm{MPa}$, and (c) Precrack + SP specimens, $2 \mathrm{c}=51 \mu \mathrm{m}, \sigma_{B}=1250 \mathrm{MPa}$. 
Table 1 Shot peening condition

\begin{tabular}{ll}
\hline Shot system & Direct pressure system \\
\hline Shot material & $\mathrm{ZrO}_{2}$ beads $(1150 \mathrm{HV})$ \\
Shot diameter & $\Phi 180 \mu \mathrm{m}$ \\
Shot pressure & $0.2 \mathrm{MPa}$ \\
Time & $30 \mathrm{sec}$ \\
Coverage & $300 \%$ \\
\hline
\end{tabular}


Table 2 Conditions for X-ray diffraction analyses

\begin{tabular}{ll}
\hline Characteristic X-ray & $\mathrm{Cu} \mathrm{K \alpha} \alpha_{1}$ \\
X-ray tube & $\mathrm{Cu}$ \\
Diffraction plane & $\mathrm{ZrO}_{2}\left(\begin{array}{ll}0 & 26\end{array}\right)$ \\
Diffraction angle & $140.48^{\circ}$ \\
Tube voltage & $40 \mathrm{kV}$ \\
Tube current & $30 \mathrm{~mA}$ \\
\hline
\end{tabular}


Table 3 Half width $\left(\begin{array}{lll}0 & 0 & 1\end{array}\right)_{t}$, monoclinic weight fraction, and integrated intensity for the different shot pressures.

\begin{tabular}{c|c|ccc}
\hline $\begin{array}{c}\text { Shot pressure } \\
{[\mathrm{MPa}]}\end{array}$ & $\begin{array}{c}\text { Half width } \\
\left(\begin{array}{lll}0 & 0 & 1\end{array}\right)_{\mathrm{t}} \\
{[\mathrm{deg}]}\end{array}$ & $\begin{array}{c}I_{m} \\
{[\mathrm{cps} \cdot \mathrm{deg}]}\end{array}$ & $\begin{array}{c}I_{t} \\
{[\mathrm{cps} \cdot \mathrm{deg}]}\end{array}$ & $\begin{array}{c}X_{m} \\
{[\%]}\end{array}$ \\
\hline Non-SP & 0.2403 & - & 131962 & 0.0 \\
0.2 & 0.5053 & 6439 & 109180 & 5.6 \\
0.4 & 0.5657 & 12045 & 127050 & 8.7 \\
0.6 & 0.6278 & 11679 & 110090 & 9.6 \\
\hline
\end{tabular}




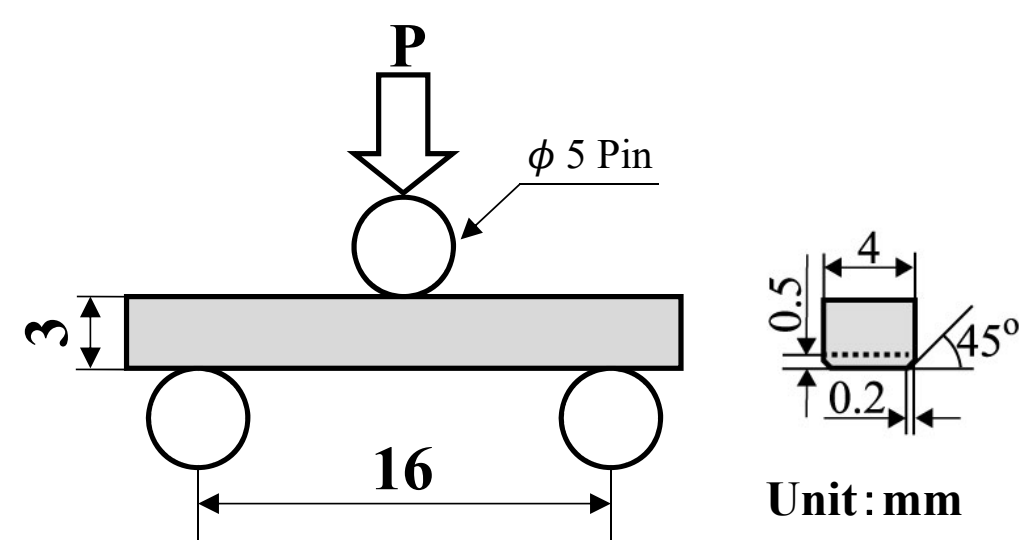

Fig. 1 Schematic drawing of the three-point loading system, test specimen size, and machining configuration. 


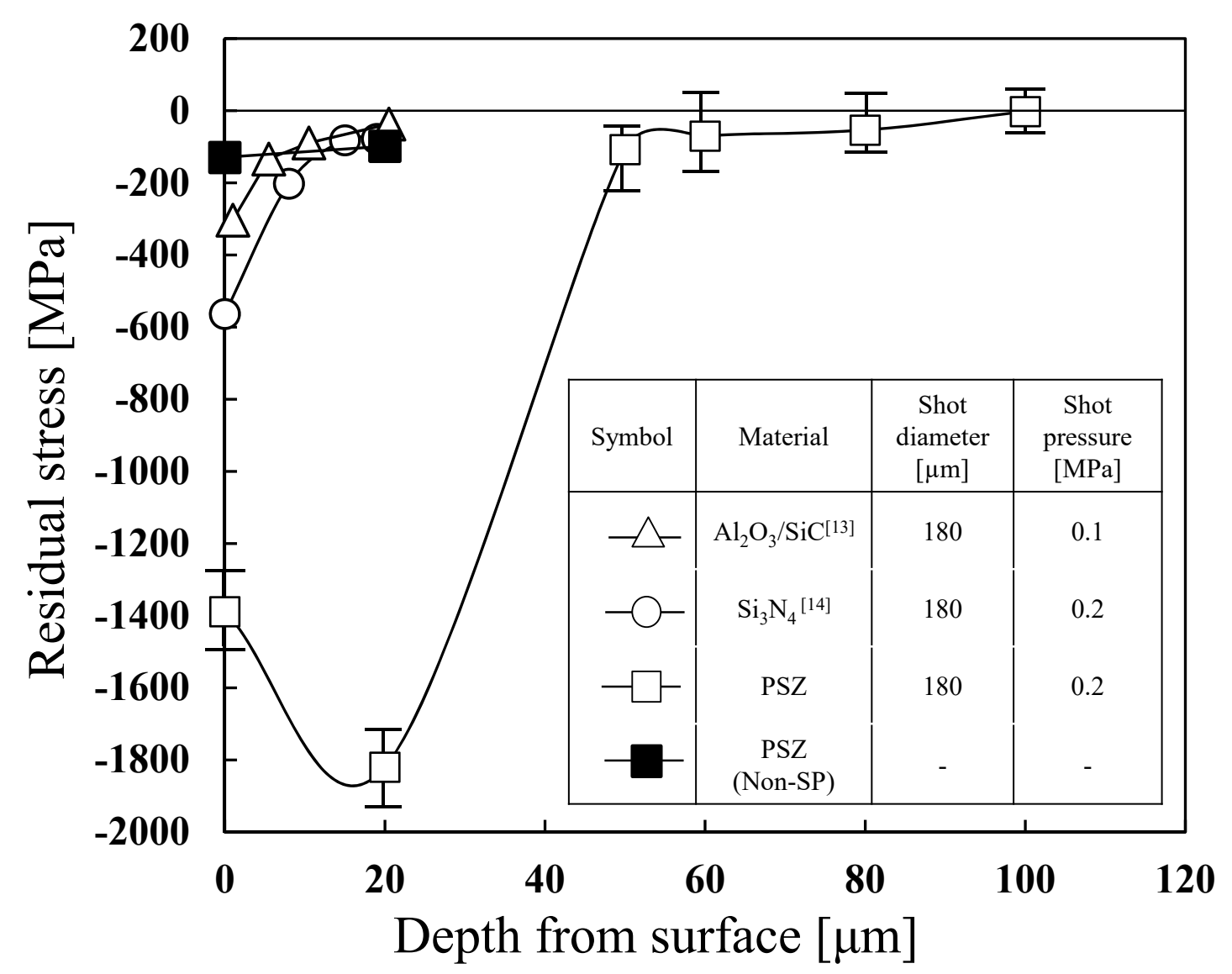

Fig. 2 Relationship between residual stress and depth from surface. 


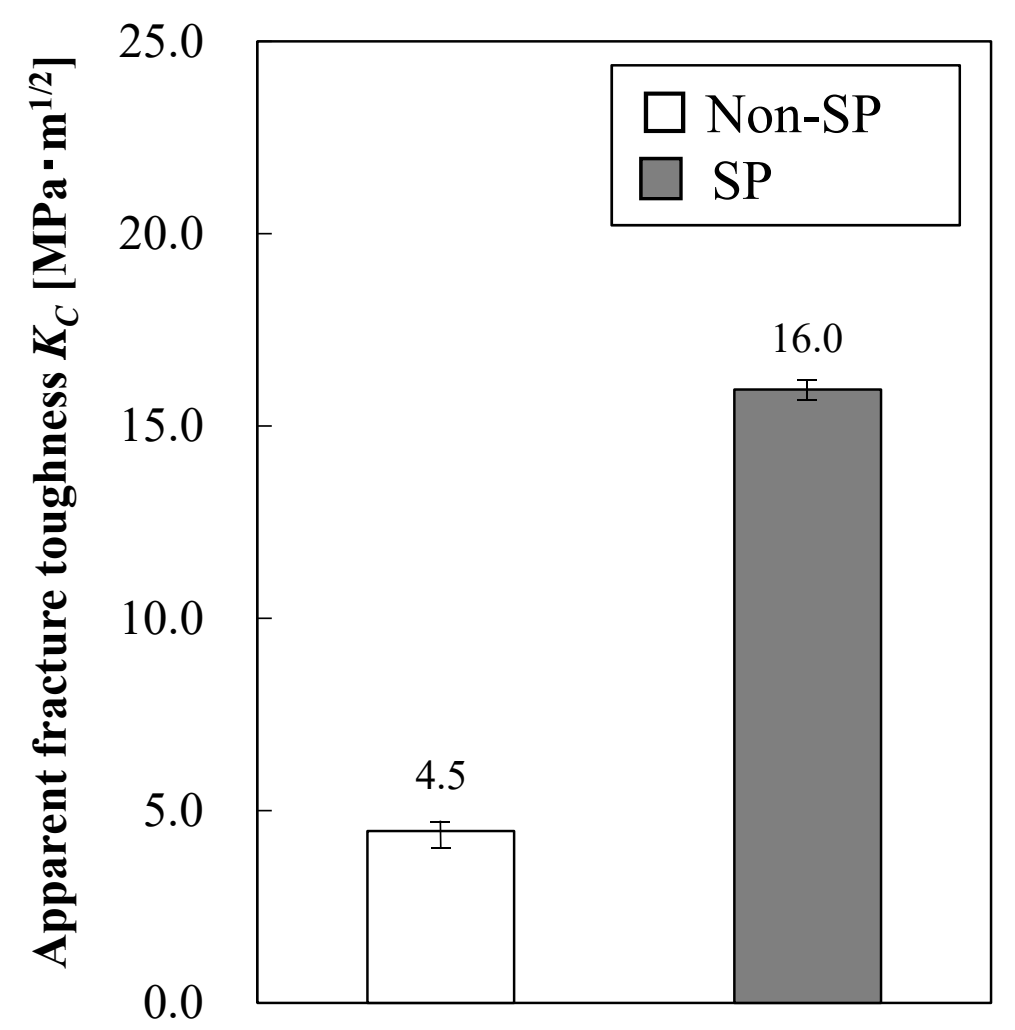

Fig. $3 K_{\mathrm{C}}$ values of the different surface-treatment specimens. The error bar indicates standard deviation. 


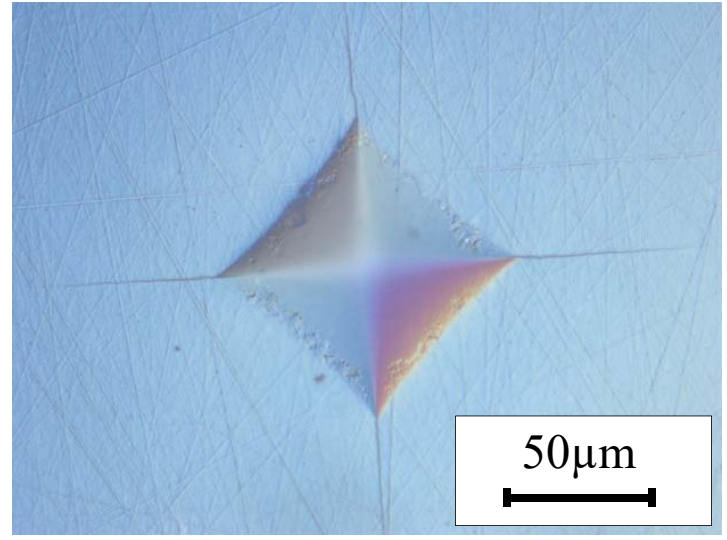

(a)

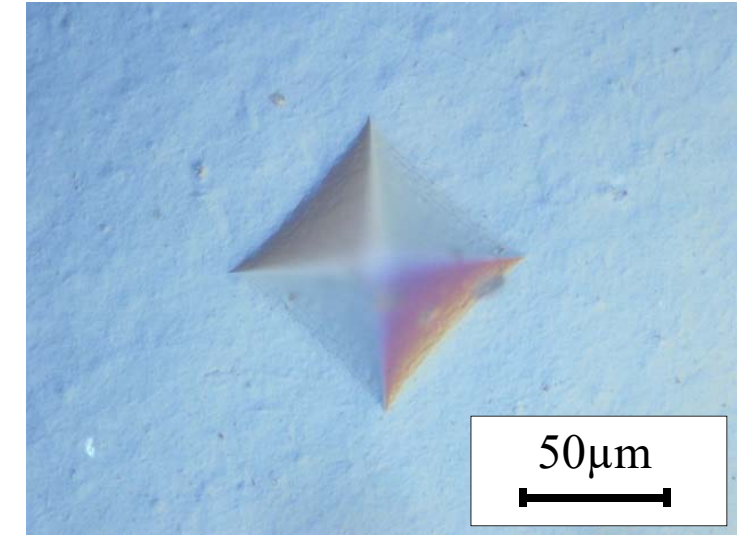

(b)

Fig. 4 Photograph of Vickers indentations and cracks in the (a) Non-SP and (b) SP specimens. 


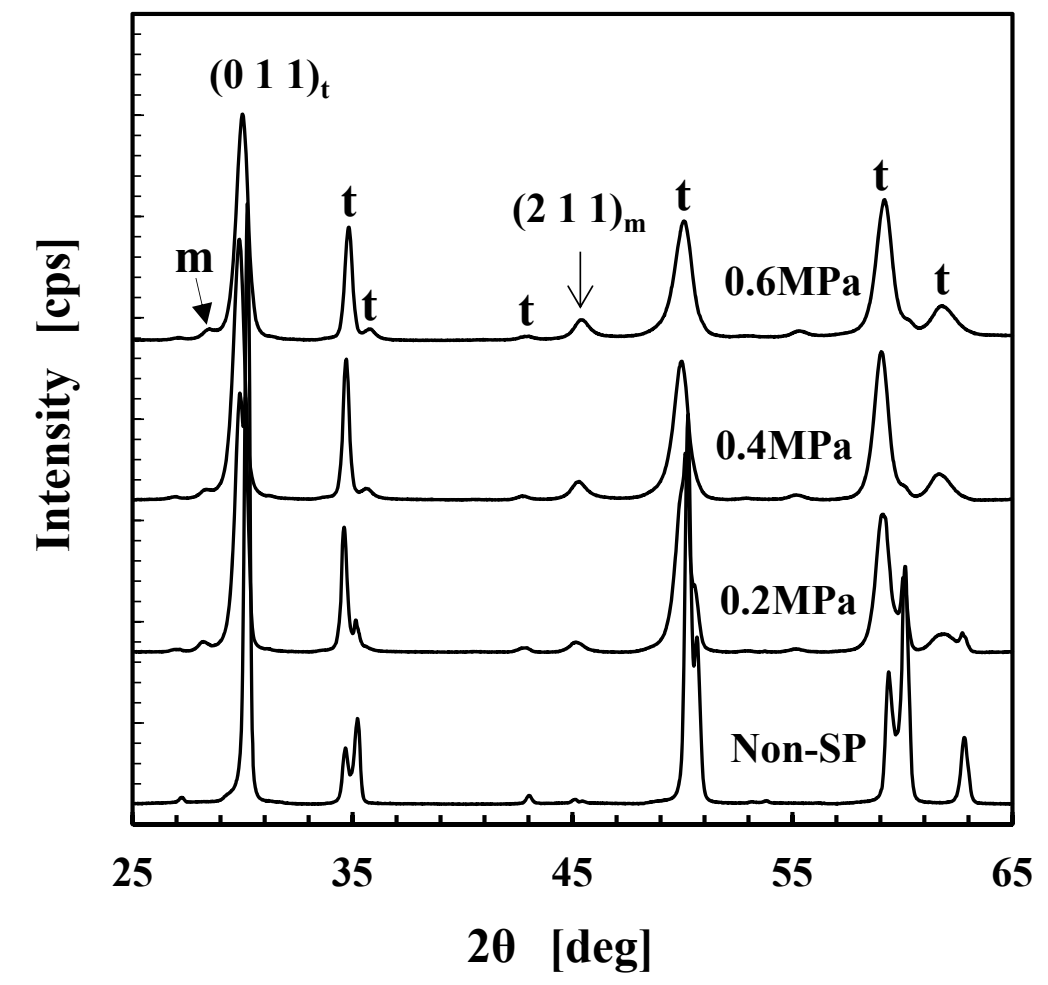

Fig. 5 XRD pattern of the surface of a peened PSZ specimens. 


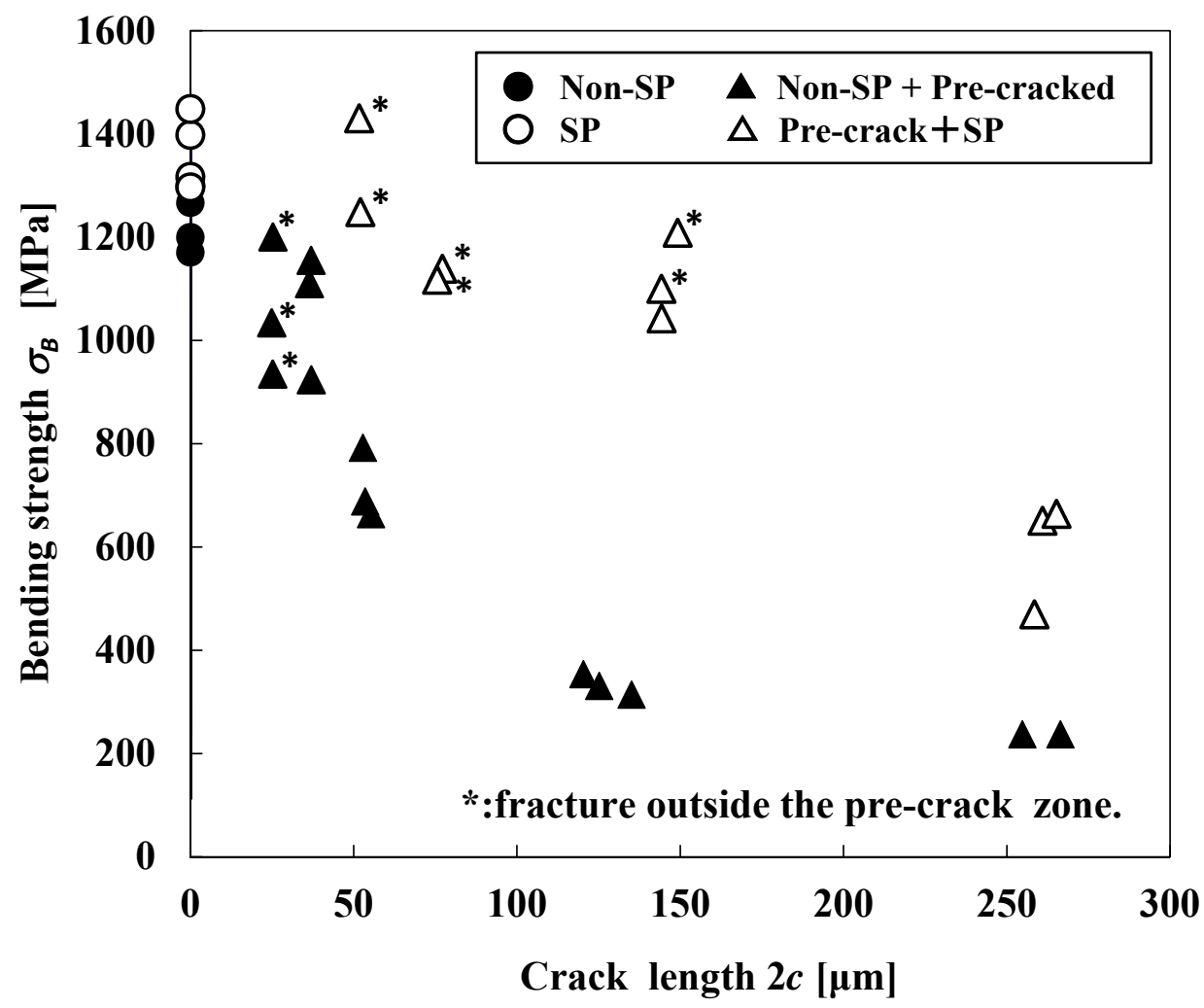

Fig. 6 Relationship between bending strength and crack length. 


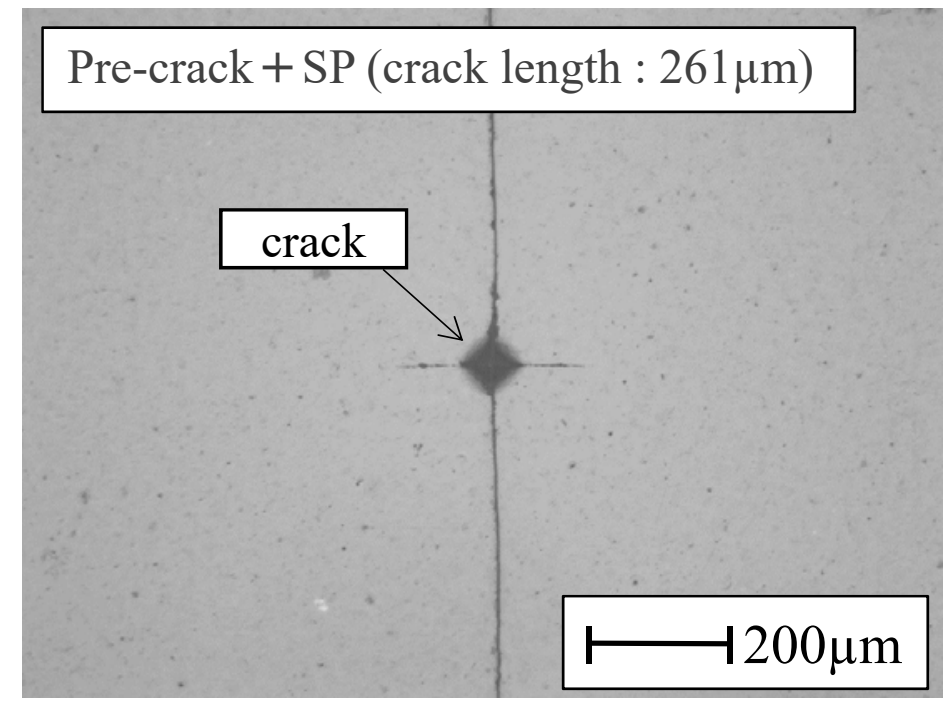

(a)

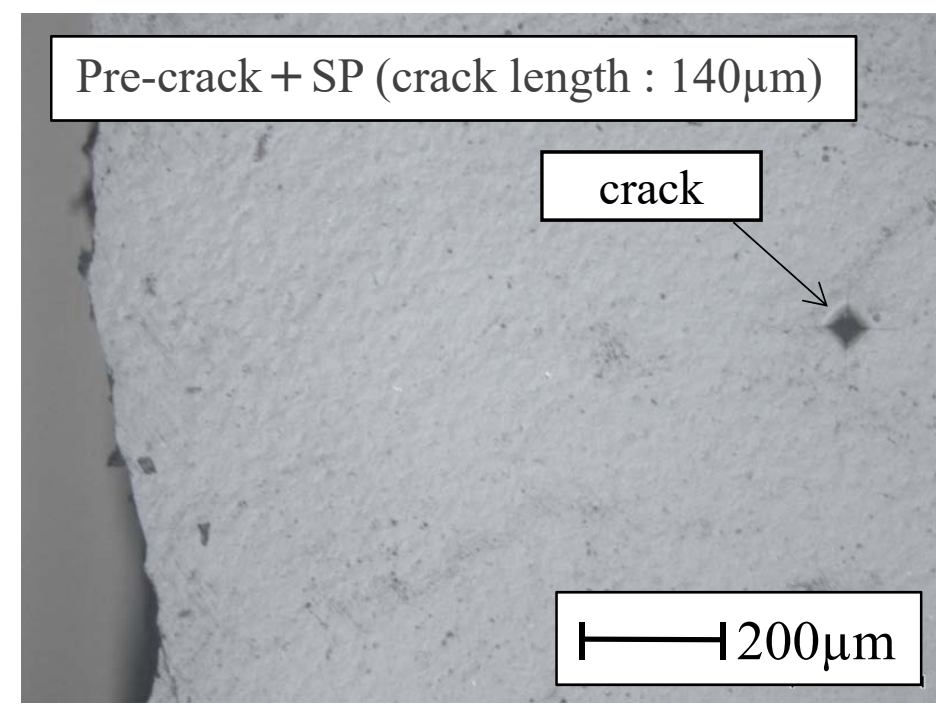

(b)

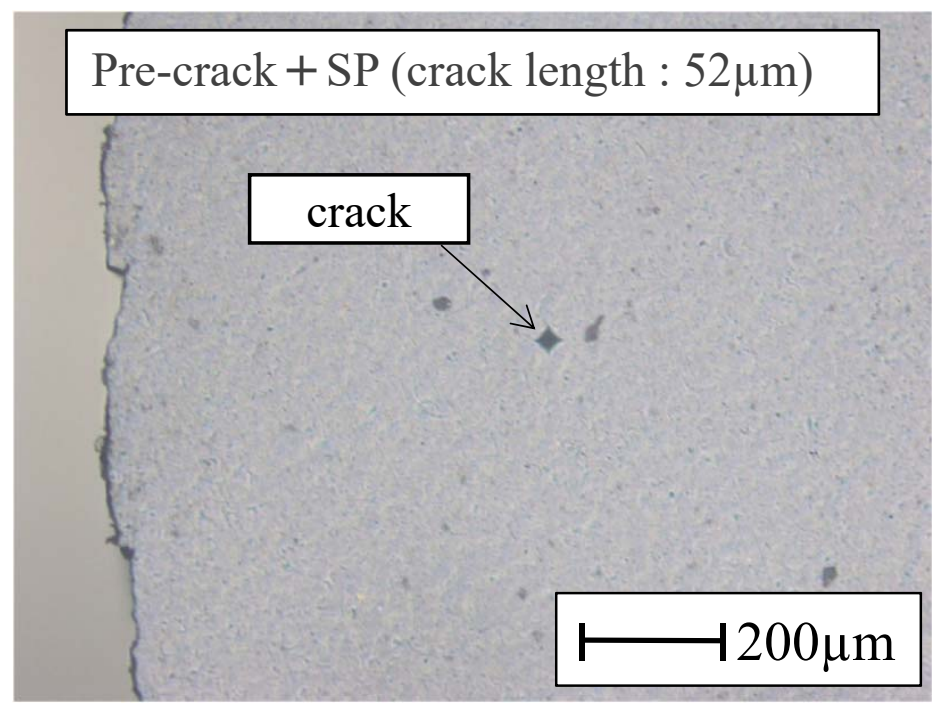

(c)

Fig. 7 Surface of Pre-crack + SP specimens after the bending test; bending strengths and crack lengths of (a) $\sigma_{B}=651 \mathrm{MPa}$ and $2 \mathrm{c}=261 \mu \mathrm{m}$, (b) $\sigma_{B}=1100 \mathrm{MPa}$ and $2 \mathrm{c}$ $=140 \mu \mathrm{m}$, and (c) $\sigma_{B}=1431 \mathrm{MPa}$ and $2 c=52 \mu \mathrm{m}$. 


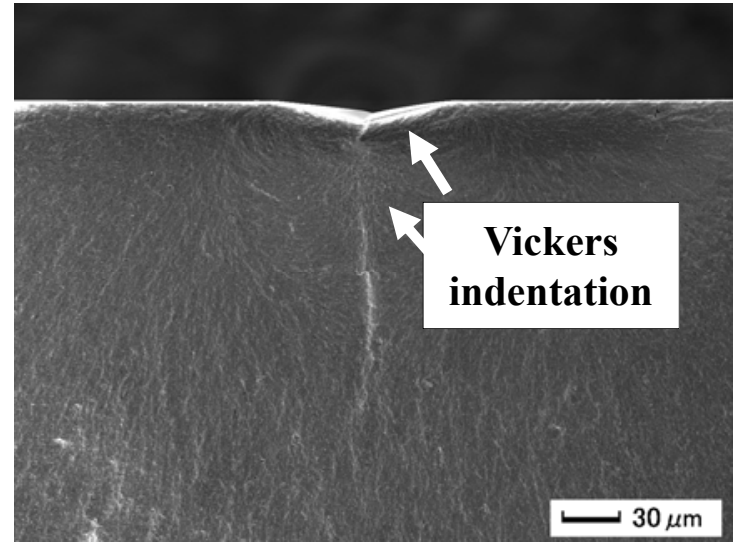

(a)

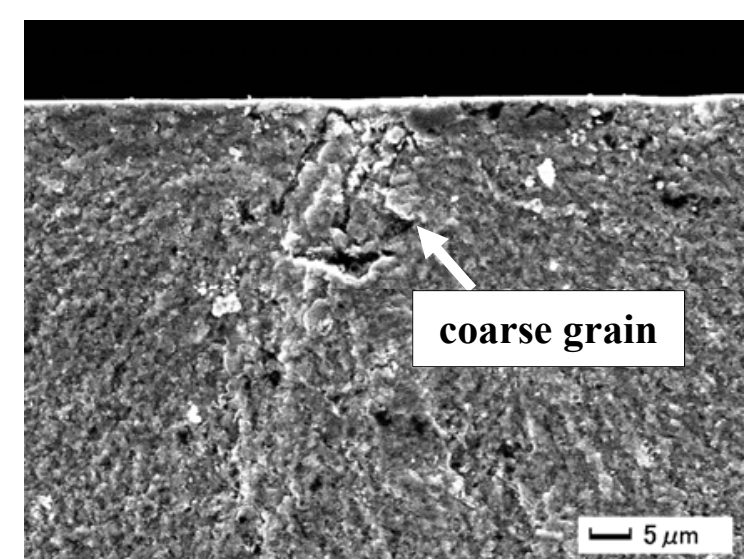

(b)

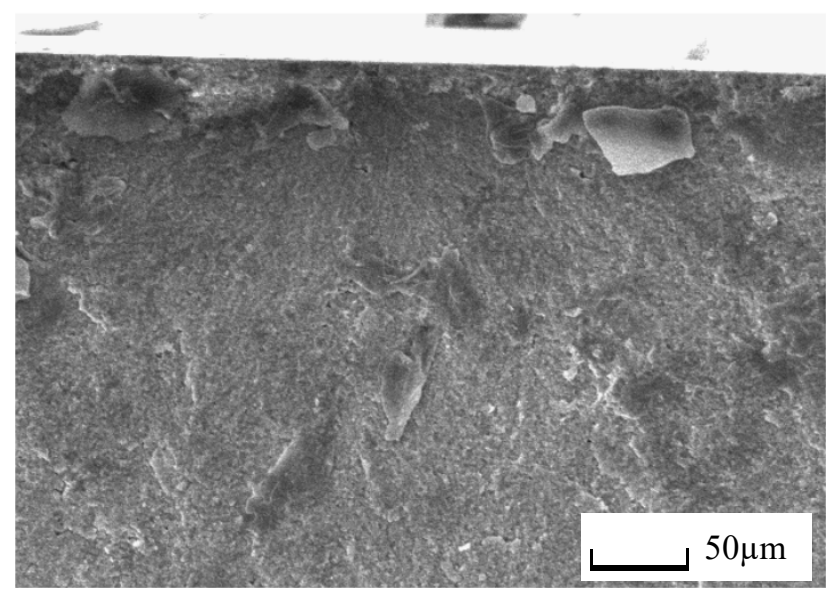

(c)

Fig. 8 SEM images showing the origins of fractures: (a) Pre-cracked specimen, $2 \mathrm{c}=120 \mu \mathrm{m}$, $\sigma_{B}=354 \mathrm{MPa}$, (b) Pre-crack + SP specimens, $2 \mathrm{c}=140 \mu \mathrm{m}, \sigma_{B}=1100 \mathrm{MPa}$, and (c) Precrack + SP specimens, $2 \mathrm{c}=51 \mu \mathrm{m}, \sigma_{B}=1250 \mathrm{MPa}$. 